\title{
The neutrino and the whale
}

\section{An underwater effort to detect subatomic particles has ended up detecting sperm whales instead. Nicola Nosengo reports on a partnership between marine biologists and particle physicists.}

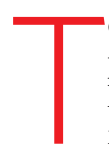

o the dock workers and sailors at the port of Catania, in Eastern Sicily, it all looked very suspicious. About once a month during 2005 and 2006, two strangers would walk out to a large wooden cabin at the end of a pier, unlock the door, and remove a small box. Then they would lock up again and disappear until the next month.

The locals had to question what the two men were up to. But when asked, the strangers reassured them that there was nothing to worry about. They were scientists. And the boxes they were retrieving were computer hard drives containing hours of sound data relayed by an underwater cable from microphones - or, more accurately, hydrophones - placed on the Mediterranean sea floor

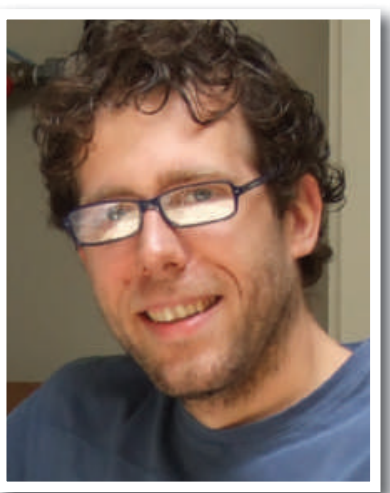

Riccobene: a particle physicist. vae. But these fundamental particles have no electric charge and have masses close to zero; they interact with matter so rarely that studying them requires gigantic detectors - the bigger, the better. Hence the NEMO design calls for thousands of optical detectors distributed over 2 cubic kilometres of water, 3,500 metres under the sea at a site off Capo Passero in southern Sicily. The idea is that an incoming neutrino will very occasionally interact with a water molecule, producing a pulse of light that the detectors will capture.

Riccobene was working on a way to enhance the detection. "Theoretically, higher-energy neutrinos should also produce detectable sound waves," he says. "As sound travels better than light in water, an acoustic 28 kilometres offshore. Giorgio Riccobene, a particle physicist at the Southern Laboratories of the Italian National Institute for Nuclear Physics (INFN) in Catania, was hoping to show that the hydrophones could be used to detect subatomic particles called neutrinos that had come from deep space. Giovanni Pavan, a marine biologist from the University of Pavia in Northern Italy, was there to help Riccobene deal with background noise in the recordings.

But what Riccobene and Pavan discovered as they listened to their data will bring them back to the port next year with their roles reversed. Then, the physicist will be helping the biologist, and their quarry will not be neutrinos, but sperm whales.

The road to this unexpected destination began nearly a decade ago with Riccobene's involvement in the Neutrino Mediterranean Observatory (NEMO), a collaboration of around 100 researchers from the INFN and other Italian institutes who are hoping to study neutrinos in the ocean. Cosmological neutrinos are constantly streaming through Earth, carrying invaluable information about distant sources such as superno-

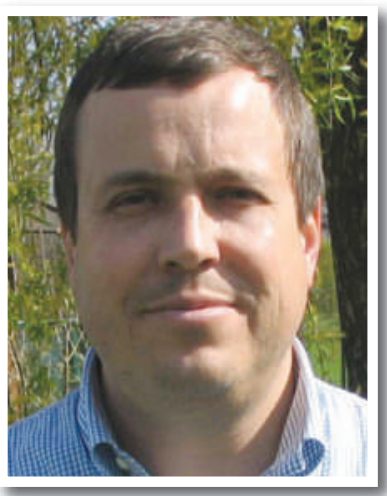

Pavan: a marine biologist. detector could multiply chances to capture neutrino events." No one knew if this would work. But as the NEMO design includes hydrophones anyway - they are needed to position the optical detectors- Riccobene was asked in 2002 to supervise a feasibility study called the Ocean Noise Detection Experiment (ONDE), which would be located at the project's 2,000-metredeep test site east of Catania.

\section{Noise control}

To educate himself, Riccobene went to Paris for a workshop about acoustic neutrino detection, and immediately noticed something missing from the talks. "Background noise was not even mentioned," he recalls. "Everyone was taking for granted that at great depths it would be very low, but there were no published data." Riccobene went back to Catania, just in time to discover that a local environmental group was hosting a talk by Pavan, who had pioneered the digital recording of sea-mammal sounds in the early 1980s, and who was acknowledged as one of the world's leading experts in the field. He was obviously the right man to answer Riccobene's question: how high would background noise be at a depth of 2,000 metres?

With little data to rely on, Pavan had no simple answer. "Systems to record at great depths were simply not available until a few years ago," he says. About all he could say for sure was that deep waters were not nearly as silent as the neutrino physicists were assuming.

"At first I was appalled," Riccobene says. The noise levels Pavan estimated were well above the expected level of a neutrino event. That did not necessarily make neutrino detection unfeasible, he says. But it did mean that the NEMO team couldn't hope to isolate the neutrino signals until it had an accurate survey of the background noise it would have to filter out.

Riccobene invited Pavan to join the ONDE team on a long-term monitoring project of the Sicilian seabed soundscape - the first ever attempted at such depths. Pavan had no funds to support his participation, but accepted anyway. Riccobene would give him access to depths he could never reach otherwise, allowing him to study the largely unknown acoustic environment of the deep sea. Pavan particularly hoped to measure the level of sound pollution there, as it is a potential cause of stranding for many deep-diving whales - whose vocalizations he also expected to hear in the recordings.

By January 2005, Riccobene and his team had positioned four high-sensitivity hydrophones at the NEMO test site and had laid an optical data cable back to that cabin on the pier in Catania. Soon after that Riccobene and Pavan were obtaining data. And in April 2005, Pavan began listening to the first recordings.

As he predicted, Pavan could hear low, uniform background noise, mostly caused by natural water movement and ship traffic, plus an occasional burst of identifiable sounds: the propeller of a large ship, a sonar impulse, even some explosions. But what captured his attention were short, regularly repeating sequences of 'clicks' - the signature sounds made by sperm whales compressing air through their respiratory system. "They probably use them to estimate depth and to locate prey, measuring their echoes more or less like bats do," Pavan says. Hearing clicks every now and then was not surprising: they are among the loudest sounds produced by any animal, and can travel up to 20 kilometres in water. What was surprising was that the clicks kept appearing in the recordings month after 


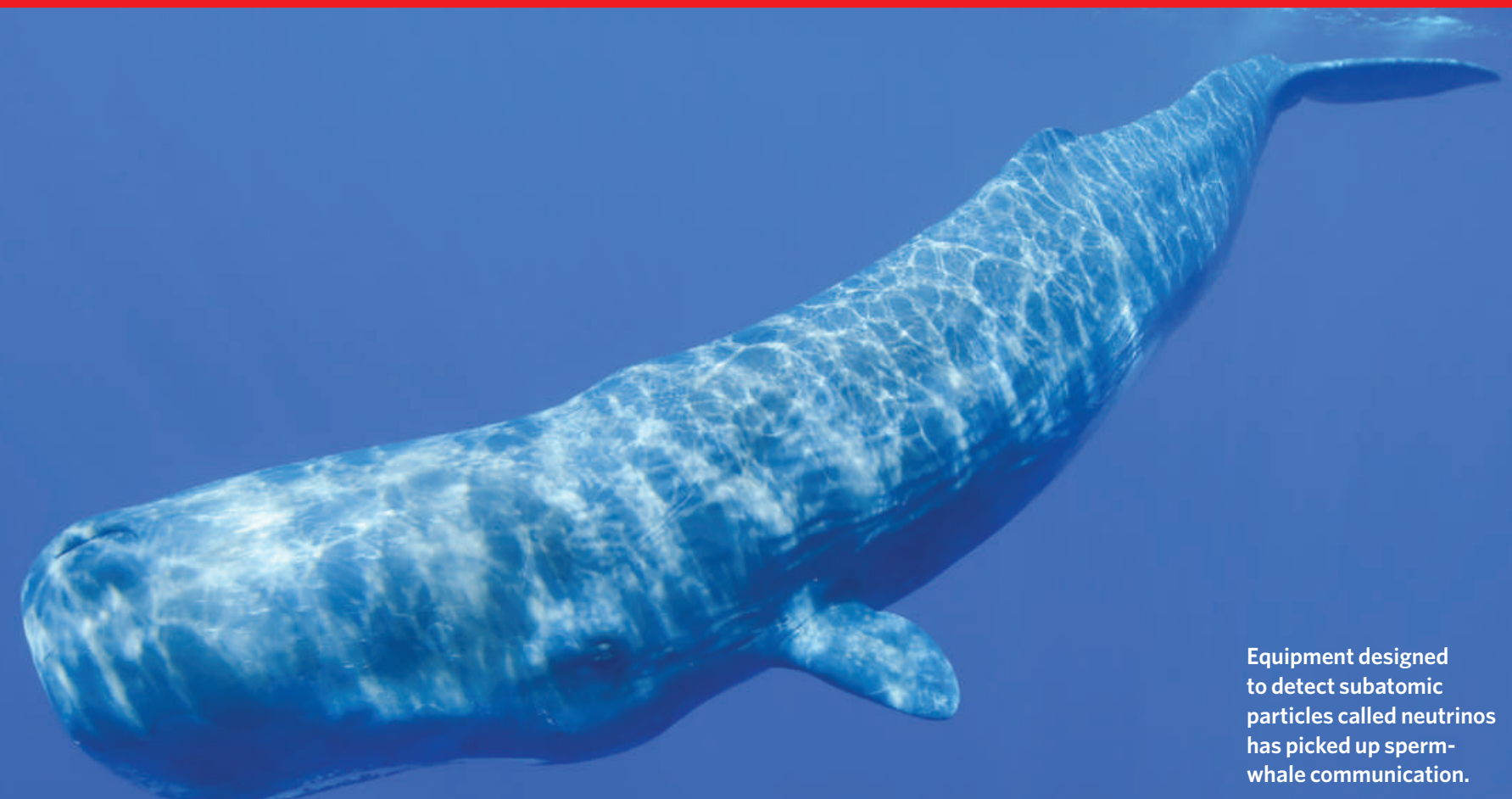

month. "Sperm whales are considered very rare in this area," Pavan says. "Published data hint at a very sparse population." But these studies are usually based on sightings or sound recordings taken near the sea surface. The ONDE recordings came from the deep waters where sperm whales dive for food and spend most of their

3 time, suggesting that the creatures could be much more abundant in this area than previously thought.

Riccobene and Pavan kept recording until November 2006, when the hydrophones were removed and replaced by a prototype of the optical detection system, which was connected to the same cable. By that point the two scientists had collected more than 600 hours of recordings, and although they hadn't detected any neutrinos, they were satisfied. "My interest at the time was in proving that deep underwater recording was feasible, and could produce data of good quality," Riccobene says. "I did not expect to detect neutrinos at this stage." At the same time, Pavan now realized he could get much more from the data than a simple list of background noise sources.

Yet hearing sperm whales is one thing. Counting them and compiling reliable statistics is another. In principle, the acoustic properties of a click can give an idea of the animal's size and sex. And if the click's reflection from the sea surface also shows up in the recording, it is possible to estimate the animal's position and its ascending or descending trajectory. "But either you develop a software algorithm to do this, or you do a long and awful hand count," Pavan says - and the latter is exactly what he and his colleagues have been doing since 2006, as they had no funding to pay for such algorithms.

Still, Pavan says, a statistical picture has slowly begun to emerge. Sperm whales appear in half of the recorded days, something existing population estimates cannot account for. Pavan and his colleagues have also been able to detect seasonal patterns and hints of social behaviour in the recordings - data they presented at a conference in Pavia in September. "Whales are more frequent in spring and autumn, with more animals moving at the same time, probably belonging to the same school," Pavan says. Sometimes the recordings contain 'codas', brief sequences of clicks with a peculiar pattern. These sounds are thought to have a social function, as they are emitted only when males, normally solitary, gather around female groups. Codas seem to work as local dialects, with different populations using different patterns. "The most frequent pattern in the Mediterranean is the $3+1$ type," says Pavan, "a rapid succession of three clicks and then an additional one." But the recordings show that a $2+1$ type is more frequent than expected, which could hint at whales in transit from outside the Mediterranean basin.

\section{Deep-down disturbances}

Meanwhile, Riccobene, by now an enthusiast of bioacoustics almost as much as of neutrino physics, has managed to set up a continuation of the study by involving the European Seas Observatory Network (ESONET), a European collaboration that is developing a network of deep-sea monitoring stations in the Mediterranean. Although ESONET's focus is on geophysics and climatology, it has agreed to finance a new incarnation of the ONDE platform called LIDO (Listening Into the Deep Ocean). LIDO will last for three years, starting next March when an array of four hydrophones will once again be deployed off Catania to listen for whales. This time, continuous recording ses- sions will last for up to one year, and algorithms will be used to choose which data to keep and which to disregard. Detailed comparisons of recordings from the four hydrophones, placed on the vertices of a square, will allow researchers to determine each detected animal's size, speed and direction, and give a more precise estimate of sperm-whale populations and seasonal habits. In the future, the project envisages the deployment of similar stations at other locations, including the Gulf of Cádiz, close to the Strait of Gibraltar. "One of our key problems is to understand whether Mediterranean sperm whales are a closed population, or whether there is an exchange with the oceanic population," Pavan says.

Riccobene and his colleagues are also continuing their work on the final, large-scale NEMO observatory. If all goes as the developers hope, it will be deployed before the end of the next decade off Capo Passero. The larger project will include an acoustic system, at least for positioning purposes if not for detection. Riccobene now knows there is plenty of background noise in deep waters, but he has decided that he needs more data to work out whether he can detect neutrinos acoustically, and that depends on winning more funds. And NEMO's data will be shared with biologists, seismologists and any other interested researchers. Pavan will surely be among them, eager to study not just sperm whales but also fin and beaked whales, whose low frequencies are best heard at greater depths.

"Sea floors at such depths are among the least-known regions of the planet, and there is a lot down there for many researchers," Riccobene says. "Once we put a broadband connection 3,500 metres under the sea, I have a feeling people will queue up for the data." Nicola Nosengo is a freelance science writer based in Rome. 